\title{
Is elongated styloid process a potential forewarning for failure in oral submucous fibrosis management?
}

\section{Shital Mayank Patel*, Deval Shailesh Mehta, Taher Abbas Rupawala, Naiya Hitesh Shah, Sanjay Vinubhai Makwana, Kruna Kantibhai Bhimani}

\begin{abstract}
Department of Oral and Maxillofacial Surgery, Ahmedabad Municipal Corporation Dental College and Hospital, Ahmedabad, Gujarat, India
\end{abstract}

Received: 24 October 2020

Revised: 02 December 2020

Accepted: 03 December 2020

\author{
*Correspondence: \\ Dr. Shital Mayank Patel, \\ E-mail: drshital18.dp@gmail.com
}

Copyright: (C) the author(s), publisher and licensee Medip Academy. This is an open-access article distributed under the terms of the Creative Commons Attribution Non-Commercial License, which permits unrestricted non-commercial use, distribution, and reproduction in any medium, provided the original work is properly cited.

\begin{abstract}
Oral submucous fibrosis is a widespread, premalignant disorder causing severe difficulty in mastication and speech. With high rate of malignant conversion, it demands aggressive surgical therapy followed by mandatory long-term physiotherapy. An elongated styloid process, if present, could pose a strong hindrance to movement of mandible, leading to complete relapse of trismus in such cases. The purpose of this report is to elaborate on such co-existence in patients having oral submucous fibrosis using digital orthopantomogram. 3 patients suspected to have an elongated styloid process were referred to maxillofacial surgical unit and diagnosed with grade 4A oral submucous fibrosis. Digital orthopantomogram revealed elongated styloid process which was measured using the C. S. imaging software 7.0.3. Consequently, patients were operated by a team of maxillofacial surgeons and otolaryngologists to relieve trismus and tonsillo-styloidectomy respectively. The measured lengths of the styloid process on digital orthopantomogram were considered elongated, if exceeding the normal length of $30 \mathrm{~mm}$. The measured lengths of the styloid process were found to be at $52.7 \mathrm{~mm}, 50.1 \mathrm{~mm}$ and $57 \mathrm{~mm}$ on the right side and $51 \mathrm{~mm}, 46.8 \mathrm{~mm}$ and $37 \mathrm{~mm}$ on left side respectively in our cases. These elongated styloid processes observed in all three cases of submucous fibrosis indicates that progressive fibrosis may exert significant influence on the ossification of styloid complex. Hence, a routine preoperative screening in all patients of oral submucous fibrosis is imminent to avoid postoperative failure, pain or discomfort to the patient owing to an elongated styloid process.
\end{abstract}

Keywords: Orthopantomogram, Oral submucous fibrosis, Elongated styloid process, Trismus, Pain

\section{INTRODUCTION}

Initially described by Schwartz in 1952 in five Indian females living in Kenya as atrophia idiopathica mucosae oris, oral submucous fibrosis (OSMF) has been now accepted globally as an Indian disease with over $0.2-0.5 \%$ of the national population being affected. ${ }^{1,2}$ It is a distressing, restrictive, scarring condition of the oral cavity, which may also involve the pharynx and upper third of the oesophagus. The resultant loss of fibroelasticity and stiffening of the mucosa by the formation of fibrous bands hinders the patient's ability to enjoy normal diet or maintain oral hygiene. ${ }^{1,3}$

Although this collagen metabolic disorder is insidious with an onset of 2-5 years duration, it has a significant rate of malignant conversion $(7-30 \%){ }^{2,4}$ Dentists, being the first point of contact for the general population, have an important task in raising awareness, early detection and management of this dangerous condition. Inspite of having being continuously battled with over a duration of sixty years using numerous pharmacological and surgical 
modalities, there remains a dearth of a concrete cure due to its enigmatic course and frequent recurrence. ${ }^{5}$

The success of treatment of OSMF is largely dictated by the undeterred post-operative physiotherapy and its initiation and duration are central towards preventing the recurrence of trismus. Aversion of the patient towards physiotherapy is primarily attributed either to negligence and underestimation of its importance or post-operative pain. ${ }^{4}$ The indispensable role of physiotherapy might also be obstructed if there is a co-existence of another debilitating condition incapacitating the patient. Such a possibility can be explored with respect to the presence of an elongated styloid process (ESP) which could contribute adversely to the failure of the treatment outcome. The aim of this report is to discuss the evaluation of such ESP in patients having OSMF through digital radiographic examination.

\section{CASE REPORT}

Prior written consent was taken from 3 patients who were referred from Department of Otolaryngology of the attached medical institute to the Department of Oral and Maxillofacial Surgery, Ahmedabad Municipal
Corporation Dental College and Hospital, Ahmedabad with complaint of trismus, pain and dysphagia. Although primarily these patients were suspected to have an ESP, as complete intraoral examination was unsatisfactory due to trismus, patients were referred to our maxillofacial surgical unit to rule out a probable odontogenic cause responsible for decreased mouth opening. All 3 patients gave history of oral destructive habits for period of more than 10 years using myriad of tobacco products. They were categorized as Grade 4A OSMF cases (according to Khanna and Andrade classification 1995) with accompanying burning sensations, difficulty in phonation and mastication. ${ }^{6}$ No evident ulceration and absence of significant findings on lymph node examination ruled out potential chances of presence of malignancy.

On an orthopantomogram (OPG), osseous changes were insignificant in the dentate regions and presence of impacted wisdom teeth was noted. An ESP was detected by measuring its length from the point where it leaves the tympanic plate of the temporal bone to its mineralised tip using the carestream imaging software 7.0.3. (Carestream Health, Inc, 2010, Rochester New York, United States). (Table 1) (Figure 1) (Figure 2) (Figure 3).

Table 1: Demographic, clinical and radiographic details of patients.

\begin{tabular}{|lllllll|}
\hline S. no. & Age (in years) & Gender & $\begin{array}{l}\text { OSF group } \\
\text { (acc. to Khanna \& } \\
\text { Andrade) }\end{array}$ & $\begin{array}{l}\text { Mouth opening } \\
(\mathbf{m m})\end{array}$ & $\begin{array}{l}\text { Length of styloid process } \\
(\mathbf{m m})\end{array}$ & Right \\
\hline $\mathbf{1}$ & 29 & Male & $4 \mathrm{~A}$ & 15 & 52.7 & Left \\
\hline $\mathbf{2}$ & 24 & Male & 4A & 20 & 51 \\
\hline $\mathbf{3}$ & 26 & Male & 4A & 4 & 57 & 46.8 \\
\hline
\end{tabular}

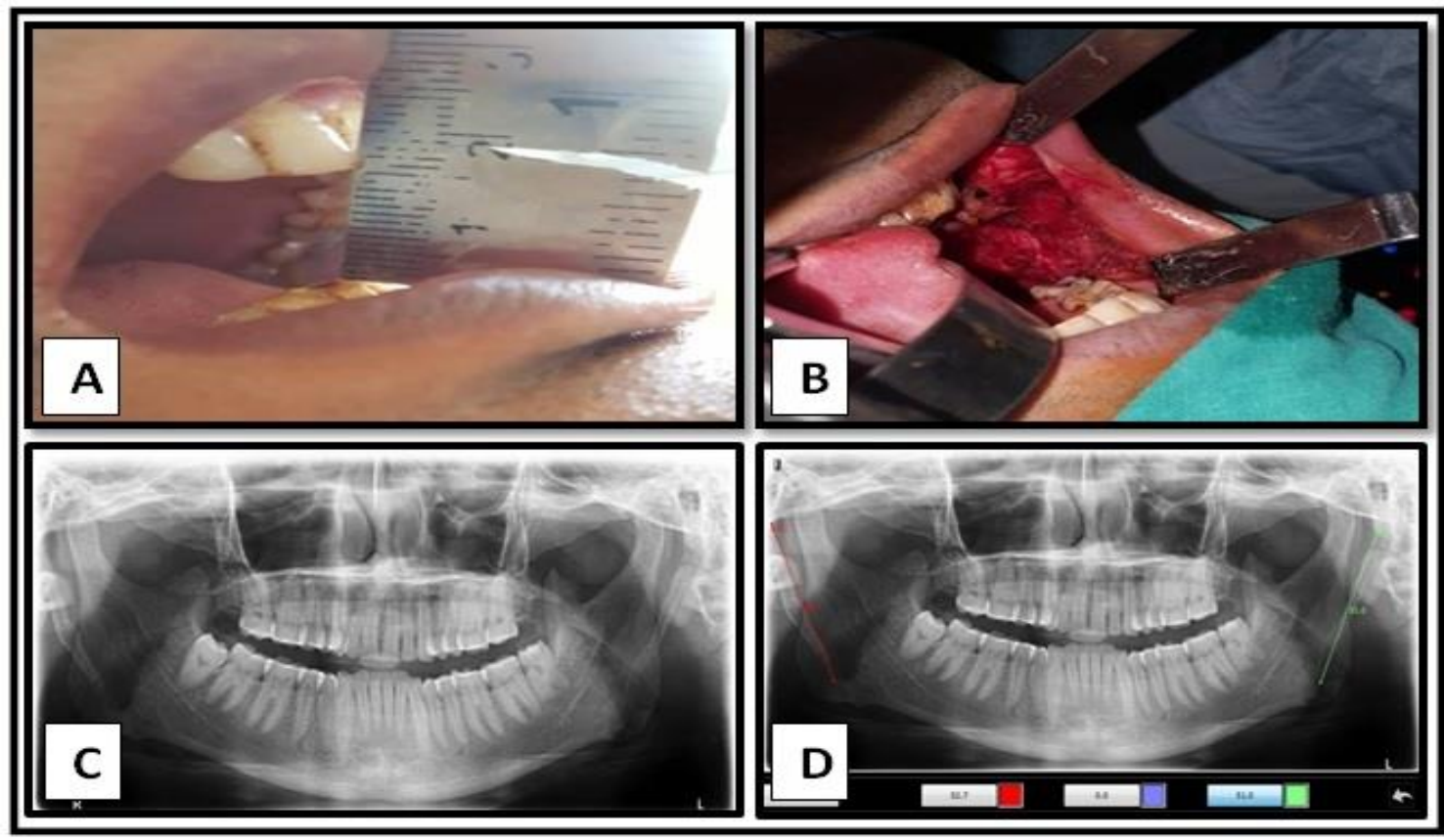

Figure 1: (A) preoperative mouth opening of patient no 1 (male aged 29 years with interincisal distance of $15 \mathrm{~mm}$ ) (B) intraoperative fibrotomy is done (C) orthopantomogram showing elongated styloid process (D) orthopantomogram showing measured styloid process. 
As panoramic radiographs were extraorally placed, conveniently available with low radiation exposure and displayed the entire maxillofacial unit, they were chosen as the preferred radiographic modality. Furthermore, as an ESP with orientation in the anteromedial direction could be a potential source of pain, it was ruled out using computed tomographic scans of our patients.

The digital OPGs were recorded using the KODAK 8000 digital panoramic system (Mumbai, India) which operates using the KODAK dental imaging software and Acquisition interface module through standard exposure parameters as instructed by the manufacturers. The measured lengths of the styloid process were found to be at $52.7 \mathrm{~mm}$ and $50.1 \mathrm{~mm}$ and $57 \mathrm{~mm}$ on the right side and $51 \mathrm{~mm}, 46.8 \mathrm{~mm}$ and $37 \mathrm{~mm}$ on the left side respectively (Table 1).

The sampled lengths were considered to be elongated as the normal radiographic length is considered to be 30 $\mathrm{mm} .{ }^{7}$ All patients were operated with a multi-disciplinary approach as follows- patient no 1 and 2 were treated with intraoral fibrotomy (Figure 1,2) whereas patient no 3 was managed with a placement of a nasolabial graft post fibrotomy (Figure 3) by a team of oral and maxillofacial surgeons. Later on, discharge from the oral surgical ward, all 3 patients were referred back to Department of Otolaryngology wherein tonsillo-styloidectomy was accomplished by the otolaryngology counterparts.

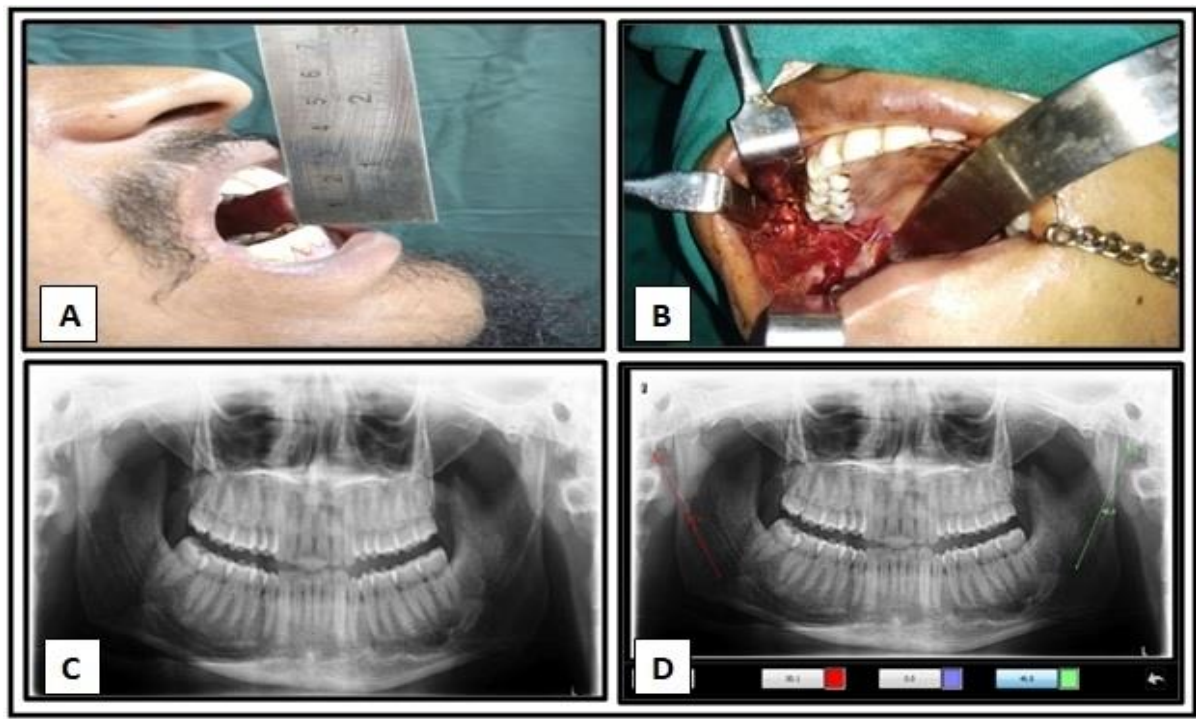

Figure 2: (A) preoperative mouth opening of patient no 2 (male aged 24 years with interincisal distance of $20 \mathrm{~mm}$ ) (B) intraoperative fibrotomy is done (C) orthopantomogram showing elongated styloid process

(D) orthopantomogram showing measured styloid process.

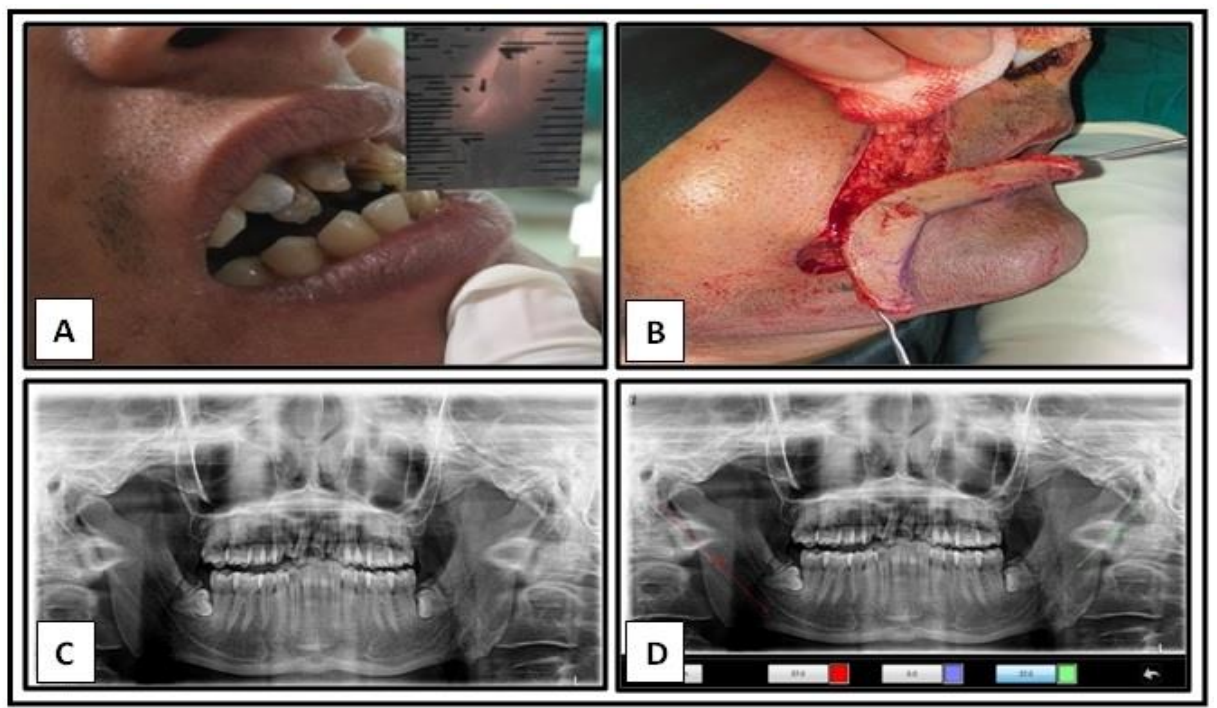

Figure 3: (A) preoperative mouth opening of patient no 3 (male aged 26 years with interincisal distance $4 \mathrm{~mm}$ ) (B) intraoperative harvest of nasolabial flap (C) orthopantomogram showing elongated styloid process (D) orthopantomogram showing measured styloid process. 


\section{DISCUSSION}

Over several years OSMF has been rightly considered as a chronic, resistant and crippling condition of the oral mucosa which may be initiated as a severe burning sensation of the oral mucosa, ulceration or pain. The disease gradually sets in to produce blanching, a leathery texture of the mucosa, depapillation and reduced movements of the tongue, sunken cheeks and consequently pronounced trismus. ${ }^{8}$ The fear of the administration to adversely affect the livelihood of tobacco producers and sudden spurt in the industries involved with tobacco packaging and advertising over the last few decades has resulted in nearly $0.2-1.2 \%$ of the population suffering from this condition in the Indian Subcontient. ${ }^{5,9}$ High prevalence of this condition is observed in females (1.2-4.57\%) and collectively it poses a major threat for the occurrence of oral cancer in SouthEast Asia as over $90 \%$ of premaligant lesions routinely undergo malignant conversion. ${ }^{8,10}$ Rampant consumption and usage of the initiators of the disease such as chilies, arecanut and tobacco products confluent with the prevalence of its promoters such as anemia, vitamin deficiencies, malnutrition and immunologic derangements lead to fibroblast proliferation, increased collagen synthesis and stabilization of extracellular matrix, generally in the age groups of 20-40 years. Genetic polymorphism predisposing to OSMF and role of collagen related genes have also been implicated in an attempt to decipher the etiopathogensis of this poorly understood disease. . $^{5,11,12}$

The constant irritation and trauma induced on the mucosa as a result of the chewing of arecanut or tobacco preparations has profound effect on the orientation as well as the biology of the collagen fibers. Below a normal mucosa, the fibrils are thin and haphazardly arranged in contrast to OSMF wherein they form thick bundles of 20$30 \mu \mathrm{m}$ and reorganize in a parallel and vertical direction to the epithelium according to the direction of stress induced by the opening and closing of the mouth during chewing. 5 Additionally, the constant trauma allows chronic inflammatory process to begin with activation of T-cells and macrophages at the site resulting in the proliferation of mediators such as interleukin-6, interferon- alpha and transforming growth factor-beta (TGF- $\beta$ ). TGF- $\beta$ works at the core of the entire process as it decelerates the degradation of collagen and promotes the deposition of insoluble collagen leading to clinical manifestations of trismus and difficulty in movements of the lower jaw. ${ }^{11,13}$

Separately, an American otolaryngologist Eagle described styalgia as an autonomous anomaly related to an ESP due to mineralization of stylohyoid ligament complex. ${ }^{14,15}$ The styloid process, a slender outgrowth from the base of the temporal bone, forms the stylohyoid complex along with the stylohyoid ligament and the lesser cornu of hyoid bone. It derives attachment from the styloglossus, stylohyoid and stylopharyngeus muscles lying caudally, medially and anteriorly towards the maxilla-vertebro-pharyngeal recess. Although, the incidence of ESP in common population has been asserted to be ranging from $4 \%$ to $28 \%$ by previous studies, only a small portion (4\%) of this group is said to be symptomatic. ${ }^{16-18}$ A clear female preponderance is elicited in literature regarding an ESP in age groups of 30-40 years associated with endocrinal alterations during the peri-menopausal period causing ossification of ligaments. ${ }^{18,19}$ Multiple other theories have been put forth to decipher the mechanism explaining the anomalous presentation of ESP such as genetic predisposition, agerelated ossification of ligaments, history of trauma, as a result of reactive hyperplasia or metaplasia or a simple anatomic variance. ${ }^{18,20}$ The basis of these propositions can be traced in the origin of the styloid process which is derived from the second branchial arch i.e. Reichert's cartilage. Under normal circumstances, the numerous foci of ossification in the Reichert's cartilage are often concluded by the age of 5-8 years. Occasionally, the ceratohyle part retains some embryonic cartilaginous tissue which matures to bone at a later age forming an osseous inelastic clasp causing symptoms of Styalgia. ${ }^{21,22}$

The clinical presentations of styalgia are often a cause of unending pain and suffering for the patient often due to misdiagnosis and previously failed treatments even by experienced clinicians. This is so because the patients often complain of dull constant nagging recurrent pain in oropharynx, dysphagia, otalgia, headache, pain on neck rotation. These symptoms, often being non-specific in location or origin can be also seen overlapping with associated temporomandibular joint dysfunctions, muscular inflammation, otitis media, pharyngeal infections and chronic denegerative and inflammatory conditions causing irritation of the sympathetic nerves. ${ }^{23}$ This implies that tremendous importance be given to attentive clinical examination corroborated with radiological findings to arrive at a precise diagnosis with specific management strategy.

This diagnostic dilemma can, at times be eliminated by studying and correlating the etiopathogenesis involved in distinct clinical entities observed in the orofacial region. As discussed, earlier TGF- $\beta$ acts as a trigger following chronic irritation of the mucosa, for the genes involved in the formation and degradation of the extracellular matrix which is responsible for the formation of fibrous bands in OSMF.

Similarly, TGF- $\beta$ being a member of the Bone Morphogenic Protein, reinforces with Parathyroid related Protein to act as a maturation factor for chondrocytes to stimulate later phases of endochondral ossification. ${ }^{11,24}$ Subsequently this ossification at the proximal part of the secondary ossified ligament (tip) may produce irritation at the pharyngeal wall if directed anteromedially. ${ }^{25}$ Furthermore, the embryological proximity of the mandible (Meckel's cartilage) with the origin of the styloid process (Reichert's cartilage) insinuates that 
chronic irritation in the vicinity of the mandibular complex could cast initiation of the calcification process at the styloid region owing to the presence of TGF- $\beta .^{25}$

The common parameter assessed in the researches pertaining to the styloid process revolve around its length which has been ranged from $1.5-4.77 \mathrm{~cm}$ as observed on panoramic radiographs, while the association between the recorded length and severity of symptoms still remains obscure with regards to the general population. ${ }^{18,23,26,27}$ With respect to the ESP seen in OSMF, Shivakumar et al relates to significant association between the two conditions with $31.4 \%$ of study patients displaying an ESP and the range of elongation ranging from 31-52 mm which can be considered significantly higher as compared to earlier studies done on common population. ${ }^{13}$ This observation supports our findings of presence of an ESP in three patients and encourages further studies based on similar hypothesis to conclusively prove a positive coexistence of an ESP in patients afflicted with OSMF.

\section{CONCLUSION}

The main objective of this report was to highlight the association between the two conditions which when encountered in the preoperative setting can prove beneficial for the patient as well as the surgeon for favorable postoperative outcome. It is proposed that all dentists, oral and maxillofacial surgeons and otolaryngologists should observe for the elongation of the styloid process in the panoramic radiographs of each and every patient having OSMF. Early and preoperative detection of an ESP shall allow a single-stage surgery (fibrotomy with styloidectomy) through a multidisciplinary approach, irrespective of the approach (intraoral or extraoral for styloidectomy), to avoid surgical morbidity, undue hospitalization along with better treatment outcomes, lesser recurrence, unimpeded postoperative physiotherapy and psychological wellbeing of the patient.

\section{Funding: No funding sources Conflict of interest: None declared Ethical approval: Not required}

\section{REFERENCES}

1. Warnakulasuriya S, Tilakaratne WM, Kerr A. Oral Submucous Fibrosis. Springer In Contempor Oral Oncol. 2017:329-53.

2. Passi D, Bhanot P, Kacker D, Chahal D, Atri M, Panwar Y. Oral submucous fibrosis: Newer proposed classification with critical updates in pathogenesis and management strategies. Nation $\mathrm{J}$ Maxillofac Surg. 2017;8(2):89.

3. Tilakaratne WM, Ekanayaka RP, Warnakulasuriya S. Oral submucous fibrosis: a historical perspective and a review on etiology and pathogenesis. Oral Medic Oral Pathol Oral Radiol. 2016;122(2):17891.
4. Kale S, Srivastava N, Bagga V, Shetty A. Effectiveness of long term supervised and assisted physiotherapy in postsurgery oral submucous fibrosis patients. Case Repo Dentist. 2016;2016.

5. Hebbar PB, Sheshaprasad R, Gurudath S, Pai A, Sujatha D. Oral submucous fibrosis in India: Are we progressing? Ind J Canc. 2014;51(3):222.

6. Khanna JN, Andrade NN. Oral submucous fibrosis: a new concept in surgical management: report of 100 cases. Int J Oral Maxillofac Surg. 1995;24:4339.

7. More CB, Asrani MK. Evaluation of the styloid process on digital panoramic radiographs. Ind $\mathbf{J}$ Radiol Imag. 2010;20(4):261.

8. More CB, Das S, Patel H, Adalja C, Kamatchi V, Venkatesh R. Proposed clinical classification for oral submucous fibrosis. Oral Oncol. 2012;48(3):200-2.

9. Kalvizhi EB, Charanya D, Sasirekha B, Megalaa N, Kanmani R. A review on oral Submucous Fibrosis. Int J Curr Res. 2017;9(07):55116-20.

10. Reddy V, Wanjari PV, Banda NR, Reddy P. Oral submucous fibrosis: Correlation of clinical grading to various habit factors. Int J Dent Clinic. 2011;3(1).

11. Rajalalitha P, Vali S. Molecular pathogenesis of oral submucous fibrosis-a collagen metabolic disorder. J Oral Pathol Medicine. 2005;34(6):321-8.

12. Tilakaratne WM, Klinikowski MF, Saku T, Peters TJ, Warnakulasuriya S. Oral submucous fibrosis: review on aetiology and pathogenesis. Oral Oncol. 2006;42(6):561-8.

13. Shivakumar HR, Batra J, Upasi AP, Rai KK. Evaluation of elongated styloid process in patients with oral submucous fibrosis using panoramic radiographs. J Maxillofac Oral Surg. 2014;13(4):556-9.

14. Eagle WW. Elongated styloid processes: report of two cases. Arch Otolaryngol. 1937;25(5):584-7.

15. Kar IB, Mishra N, Raut S, Singh AK. Facial pain due to elongated styloid process. Contempor Clinic Dentist. 2013;4(2):248.

16. Bozkir MG, Boğa H, Dere F. The evaluation of elongated styloid process in panoramic radiographs in edentulous patients. Turk J Med Sci. 1999;29(4):481-6.

17. Eagle WW. Elongated styloid processes: report of two cases. Arch Otolaryngol. 1937;25(5):584-7.

18. Lambor DV, Shetgaunkar RR, De Sa C. Stylalgia: Our Experience of 101 Cases Treated by Intraoral Styloidectomy. Ind J Otolaryngol Head Neck Surg. 2020:1-7.

19. Singhania AA, Chauhan NV, George A, Rathwala K. Lidocine Infiltration Test: An Useful Test in the Prediction of Results of Styloidectomy for Eagle's Syndrome. Ind J Otolaryngol Head Neck Surg. 2013;65(1):20-3.

20. Steinmann EP. Styloid syndrome in absence of an elongated process. Acta oto-laryngologica. 1968;66(1-6):347-56. 
21. Steinmann EP. A new light on the pathogenesis of the styloid syndrome. Arch Otolaryngol. 1970;91(2):171-4.

22. Keur JJ, Campbell JP, McCarthy JF, Ralph WJ. The clinical significance of the elongated styloid process. Oral Surg Oral Med Oral Pathol. 1986;61(4):399-404.

23. Chickooree D, Ram V. Eagle's Syndrome-View from the general practitioners perspective. Clin Med Diagn. 2014;4(19):9-13.

24. D'Angelo M, Sarment DP, Billings PC, Pacifici M. Activation of transforming growth factor $\beta$ in chondrocytes undergoing endochondral ossification. J Bone Miner Res. 2001;16(12):2339-47.
25. Breault MR. Eagle's syndrome: review of the literature and implications in craniomandibular disorders. CRANIO®. 1986;4(4):323-37.

26. Moffat DA, Ramsden RT, Shaw HJ. The styloid process syndrome: aetiological factors and surgical management. J Laryngol Otol. 1977;91(4):279-94.

27. Kaufman SM, Elzay RP, Irish EF. Styloid process variation: radiologic and clinical study. Arch Otolaryngol. 1970;91(5):460-3.

Cite this article as: Patel SM, Mehta DS, Rupawala TA, Shah NH, Makwana SV, Bhimani KK. Is elongated styloid process a potential forewarning for failure in oral submucous fibrosis management? Int $\mathbf{J}$ Otorhinolaryngol Head Neck Surg 2021;7:180-5. 